\title{
Medication adherence and patient satisfaction following percutaneous coronary intervention: experience of a Tertiary Care Cardiac Center in Sri Lanka
}

\author{
Hewarathna U I', Bandara H G W A P L1, Kogulan $\mathrm{T}^{1}$, Karunarathne R M S P1, Kodithuwakku N W', \\ Dolapihilla S N B ${ }^{2}$, Weerakoon $\mathbf{G}^{2}$, Mayurathan $\mathbf{G}^{2}$, Ambagaspitiya $\mathbf{D}^{3}$, Siribaddana $\mathbf{M} \mathbf{A ~ H}^{3}$
}

Journal of the Ceylon College of Physicians, 2017, 48, 26-33

\begin{abstract}
Background: Percutaneous coronary intervention (PCI) is an effective treatment modality of coronary revascularization. Since this is not curative, medication adherence with a better patient satisfaction have a major impact on final clinical outcome. This study aims to assess medication adherence and patient satisfaction following $\mathrm{PCl}$.

Method: Total of 145 patients who underwent elective $\mathrm{PCl}$ during 2014 and 2015 at Cardiology Unit, Teaching Hospital Kandy, Sri Lanka were followed up. Medication adherence was assessed using Morisky Medication Adherence Scale (MMAS-8). Patient satisfaction was assessed using Patient Satisfaction Questionnaire.
\end{abstract}

Results: Participants' mean age was $54.97 \pm$ 8.43 years and $80 \%(n=116)$ were males. Mean duration from last myocardial infarction to $\mathrm{PCl}$ was $0.89 \pm 1.84$ years. Number of drugs consumed by a person per day was $7.77 \pm 2.33$. Majority were on Aspirin (98.6\%), Clopidogrel (99.3\%) and statins $(97.9 \%)$.

According to MMAS-8, $90 \%(n=131)$ were mode-rate to high adherent to treatments. Forgetfulness (44.8\%) and inaccessibility of drugs $(13.9 \%)$ were the commonest reasons for low adherence. Low adherent to dual antiplatelet therapy was $8.3 \%(n=12)$. Majority were unaware about duration of Aspirin (78.6\%, $n=114$ ) and Clopidogrel $(85.5 \%, n=124)$ therapy. Major or minor bleeding was observed in $9 \%(n=13)$ as an adverse effect. There was no significant

\footnotetext{
1 Senior Registrar in Cardiology,

${ }^{2}$ Consultant Cardiologist,

${ }^{3}$ Research Assistant,

Teaching Hospital Kandy, Sri Lanka.

Corresponding author: Bandara HGWAPL E-mail: lakshmanbandara@gmail.com
}

association of drug non-adherence with adverse effects of drugs $\left(\chi^{2}=0.457, p=0.557\right)$.

Overall satisfaction regarding health care was $95.9 \%(n=139)$. Satisfaction about accessibility and convenience of health system was the lowest $(46.9 \%, \mathrm{n}=68)$ with a positive association with male gender $\left(\chi^{2}=3.662, p=0.043\right)$ and higher education level $\left(\chi^{2}=14.741, p<0.001\right)$. There was no association between high patient satisfaction and drug adherent $\left(\chi^{2}=0.400, p=0.702\right)$.

Conclusion: Majority of patients who underwent $\mathrm{PCl}$ had moderate to high adherence to pharmacological therapy. Even with limited resources, health system was able to provide a better $\mathrm{PCI}$ facility with high patient's satisfaction in most number of aspects.

Key words: percutaneous coronary intervention, medication adherence, patient satisfaction

\section{Introduction}

Cardiovascular diseases remain the leading cause of death worldwide, contributing to $31 \%$ of all global deaths ${ }^{1}$ and ischemic heart disease (IHD) has a major contribution on this. Age and gender standardized prevalence of IHD in Sri Lanka was reported as $9.7 \%$ by $2010^{2}$

Acute coronary syndrome (ACS) is a spectrum of diseases including unstable angina, ST elevated myocardial infarction and non-ST elevated myocardial infarction. Emergency management of ACS is by reperfusion therapy, either by fibrinolytic agents or primary percutaneous coronary intervention $(\mathrm{PCl})$. However, due to limited facilities ACS is managed medically in most of the medical centers in Sri Lanka while elective $\mathrm{PCl}$ is performed at specialized centers. Since this intervention is not curative, it has to be accompanied by long term pharmacological and non-pharmacological therapeutic measures to control further progression of ACS. Therefore, medication adherence has a major impact on patient's health status. 
Medication adherence is defined as the extent to which patients take medications as prescribed by their health care providers ${ }^{3}$. This can be influenced by patient factors, demographic variables and other associated co morbidities $^{4-6}$. Satisfactory medication adherence is important for a better health outcome as well as to minimize the health care cost.

The medication adherence can be a reflection of patient's behavior, which can be influenced by the relationship between patient and the health care provider ${ }^{3}$. A higher patient satisfaction about the health care is therefore an important determinant of the health outcome. On the other hand, the aim of health care is not only to improve the health status of an individual, but also to enumerate the quality of life by fulfilling patient needs. Therefore patient satisfaction with regard to the provided health care becomes an important direct feedback on the quality of the health care system. Patient satisfaction had been evaluated under several dimensions with different questionnaires.

Medication adherence and patient satisfaction had been assessed with regard to many medical conditions requiring long term pharmacological and nonpharmacological therapies. Conversely, there is a scarcity of data on medication adherence and patient satisfaction in post $\mathrm{PCl}$ patients.

Our objectives of this study are as follows.

1. To describe the demographic data, patient characteristics and other comorbidities

2. To assess the medication adherence and the reasons for non-adherence

3. To assess the patient satisfaction

4. To assess the association between medication adherences with different dimensions of patient satisfaction in patients who underwent $\mathrm{PCl}$ at Cardiology Unit, Teaching Hospital Kandy, Sri Lanka.

\section{Methodology}

\section{Study design and setting}

A retrospective non-randomized descriptive study was performed at Cardiology Unit, Teaching Hospital Kandy, Sri Lanka with the aim of assessing the prevalence of medication adherence and patient satisfaction in a group of patients who underwent elective PCI.

\section{Study population}

The study population consisted of a group of patients who underwent $\mathrm{PCl}$ at Cardiology Unit, Teaching Hospital Kandy, Sri Lanka during 2014 February to 2015 January and been followed up at Cardiology clinic, Teaching
Hospital Kandy, Sri Lanka. Patients who are having diagnosed psychiatric illnesses, who feel difficulty in conversing due to aggravated medical conditions as well as patients transferred to another hospital or department for further follow up were excluded. Informed written consent was obtained from all the participants who wished to take part in our study.

\section{Study instruments}

A pre-tested interviewer administered questionnaire was used to obtain information about demographic data, patient characteristics and life style modifications. Medical records and $\mathrm{PCl}$ report were used to gather information on the number and type of stents used and other co-morbidities.

The drug adherence was assessed using Morisky's Medication Adherence Scale (MMRS-08) which included eight questions, each with original binary response option $(y e s / n o)^{6,7}$. Classification of patients as high adherence, moderate adherence and low adherence were done according the total of eight answers.

For the assessment of patient satisfaction validated Patient Satisfaction Questionnaire (PSQ-18) was used ${ }^{8}$. This is an eighteen itemed questionnaire with each item accompanying five responses (strongly agree, agree, uncertain, disagree, and strongly disagree). Since wording of the items were different to each when expressing satisfaction about medical care, all the items were scored in a manner where high score implies satisfaction with medical care. All the items were assessed under seven subscales (General Satisfaction, Technical Quality, Interpersonal Manner, Communication, Financial aspect, Time spent with doctors and Accessibility and Convenience). Patients were grouped as satisfied about medical care and dissatisfied about medical care according to the summation of score.

\section{Data analysis}

Data entering and analysis was done by SPSS-19 windows statistical package. Frequency descriptive analysis was conducted for relevant socio-demographic variables.

Prevalence of medication adherence was assessed by the score obtained from MMAS- 8 questionnaire. Patients who had a score of eight out of eight were considered as high adherent while a score of six or above were classified as moderate adherent. Patients who gained a score of five or below were categorized as low adherent. Reasons for low adherence and its association with demographic factors were compared using either a standard 2-tailed t-test (for continuous variables) or a $\chi 2$ test (for dichotomous variables). 
Mean satisfaction scores was calculated for each of the seven sub scales by averaging the scores of items within each scale. Five Likert-type response categories of each item (strongly agree, agree, uncertain, disagree, strongly disagree) were scored from 1 to 5 with higher scores reflecting higher satisfaction with medical care. Average score above 3.5 for a subgroup was classified as higher satisfaction for the particular sub group whereas score below or equal to 3.5 was considered as low satisfaction.

Life style modifications such as smoking, alcohol consumption, dietary control and regular exercises were assessed with regard to the knowledge and the practices.

Ethical approval was obtained after reviewing the proposal by the Research and Ethical Review Committee, General Hospital (Teaching) Kandy.

\section{Results}

The study group consisted of 145 patients. The mean age of the group was $54.97 \pm 8.43$ years ranging from 33 to 74 years. Majority were males $(n=116,80 \%)$. Among the participants, $6.2 \%$ had received only the primary education whereas $39.3 \%$ were educated upto secondary education. Half of the study population (59.3\%) was employed while $17.2 \%$ were unemployed and $23.4 \%$ were retired. Majority (77.3\%) had to expend more than thousand rupees for their medications per month. Out of the participants, $41.4 \%$ had diabetes mellitus and most of them (85.2\%) were on oral hypoglycemic drugs where as $6.6 \%$ were on insulin therapy. There were $37.9 \%$ patients who were diagnosed with hypertension and $98.6 \%$ were diagnosed with dyslipidemia. Half of the population (53.8\%) had never smoked while $42.8 \%$ had quit smoking. Despite the fact that $93.8 \%$ were given advice to stop smoking, $3.4 \%$ do continue smoking. Alcohol consumption is continued by $15.2 \%$ and $26.2 \%$ had stopped it after $\mathrm{PCl}$. Demographic and other characteristics of study participants are listed in (Table 1).

All the patients had undergone $\mathrm{PCl}$ with a mean duration of $0.89 \pm 1.84$ years from the last coronary vascular event. Most of the patients were treated for a single coronary lesion (83.4\%) with a single stent (69.7\%). One patient was admitted with stenosis in three coronary vessels and was treated successfully with $\mathrm{PCl}$. Descriptive data on $\mathrm{PCl}$ procedure was shown (Table 2).

Through the questionnaire, we inquired whether the patients were given information regarding the $\mathrm{PCl}$. According to the responses given, $37.9 \%$ were well informed about the procedure whereas $50.3 \%$ were fairly informed. From the study group $74.5 \%$ were satisfied about the information given by the medical personnel.
Succeeding $\mathrm{PCl}$ almost all the patients were started on Aspirin (98.6\%), Clopidogrel (99.3\%) and Statins (97.9\%) while $81.4 \%$ and $75.2 \%$ were prescribed on Beta blockers and Angiotensin II converting enzyme inhibitors/ Angiotensin receptor blockers respectively. However Calcium channel blockers (14.5\%), Nicorandil (13.8\%) and Isosorbite mono nitrates (18.6\%) were less frequently prescribed among the post $\mathrm{PCl}$ population (Table 3). Average number of tablets consumed by a post $\mathrm{PCl}$ patient was calculated as $7.77 \pm 2.33$ tablets per day. There were $53.1 \%$ patients who considered post $\mathrm{PCl}$ medications are essential to continue and $44.1 \%$ continued their medications just because they were asked to do so by their medical personal.

Table 1. Participants demographic data

\begin{tabular}{|c|c|}
\hline Variable name & Result (n, \%) \\
\hline Age (mean $\pm S D)$ & $54.97 \pm 8.430$ \\
\hline \multicolumn{2}{|l|}{ Gender } \\
\hline Male & $116(80 \%)$ \\
\hline Female & $29(20 \%)$ \\
\hline \multicolumn{2}{|l|}{ Education } \\
\hline No schooling & $01(0.7 \%)$ \\
\hline Grade 1 to Grade 5 & $09(6.2 \%)$ \\
\hline Grade 6 to Grade 11 & $31(21.4 \%)$ \\
\hline Pass Ordinary Level & $47(32.4 \%)$ \\
\hline Pass Advanced Level & $48(33.1 \%)$ \\
\hline Higher Education & $9(6.2 \%)$ \\
\hline \multicolumn{2}{|l|}{ Employment } \\
\hline Unemployed & $25(17.2 \%)$ \\
\hline Employed & $86(59.3 \%)$ \\
\hline Retired & $34(23.4 \%)$ \\
\hline \multicolumn{2}{|l|}{ Monthly income } \\
\hline$<$ Rs.10000/= & $30(20.7 \%)$ \\
\hline Rs. $10000 /=$ to Rs. $20000 /-$ & $40(27.6 \%)$ \\
\hline Rs. $20000 /=$ to Rs. $30000 /-$ & $29(20.0 \%)$ \\
\hline$>$ Rs. $30000 /=$ & $46(31.7 \%)$ \\
\hline \multicolumn{2}{|l|}{ Expenses for medication per month } \\
\hline No expenses & $13(09.0 \%)$ \\
\hline$<$ Rs. $500 /=$ & 03 (02.1\%) \\
\hline$<$ Rs. $500 /=$ to Rs. $1000 /=$ & $17(11.7 \%)$ \\
\hline Rs. $1000 /=$ to Rs. $2000 /=$ & $23(15.9 \%)$ \\
\hline$>$ Rs. $2000 /=$ & $89(61.4 \%)$ \\
\hline \multicolumn{2}{|l|}{ Co-morbidities } \\
\hline Diabetes mellitus & $60(41.4 \%)$ \\
\hline Hypertension & 55 (37.9\%) \\
\hline Dyslipidemia & $143(98.6 \%)$ \\
\hline \multicolumn{2}{|l|}{ Smoking } \\
\hline Never smoked & $78(53.8 \%)$ \\
\hline Quit smoking & $62(42.8 \%)$ \\
\hline Still smoking & 05 (3.4\%) \\
\hline
\end{tabular}


Table 2. Descriptive data on PCI

\begin{tabular}{cr}
\hline Variable name & Result $(n, \%)$ \\
\hline Type of PCl & \\
Stent & $13(9.0 \%)$ \\
Stent and Balloon & $127(87.6 \%)$ \\
Balloon only & $4(2.8 \%) \mathrm{e}$ \\
\hline Number of stents & \\
1 & $101(69.7 \%)$ \\
2 & $32(22.1 \%)$ \\
3 & $9(6.2 \%)$ \\
4 & $3(2.1 \%)$ \\
\hline Number of PCl locations & \\
1 & $121(83.4 \%)$ \\
2 & $23(15.9 \%)$ \\
3 & $01(0.7 \%)$ \\
\hline
\end{tabular}

Table 3. Details on medication therapy during post $\mathrm{PCl}$

\begin{tabular}{lr}
\hline Variable name & Result $(n, \%)$ \\
\hline Aspirin & $143(98.6 \%)$ \\
Clopidogrel & $144(99.3 \%)$ \\
Statins & $142(97.9 \%)$ \\
Beta blockers & $118(81.4 \%)$ \\
ACEls or ARBs & $109(75.2 \%)$ \\
Nicorandil & $20(13.8 \%)$ \\
ISMN & $27(18.6 \%)$ \\
Calcium channel blockers & $21(14.5 \%)$ \\
\hline Total number of tablets per day & \\
(mean \pm SD) & $7.77 \pm 2.33$ \\
\hline
\end{tabular}

Pharmacological adherence was assessed both in general and specifically to dual antiplatelet therapy using MMAS - 8 questionnaire. The responses given for each item of the questionnaire were summarized in Table 4. Considering all the medication given following $\mathrm{PCl}$, $40.0 \%$ were highly adherence to treatment. Moderate adherence was noted in $50.3 \%$ and only $9.7 \%$ were low adherent to therapy. Adherence to dual antiplatelet therapy was high with $62.8 \%$ high adherence and $28.9 \%$ were moderately adherent. However, there was $8.3 \%$ who had low adherence to the dual antiplatelet therapy.

Lack of interest / forgetfulness (44.8\%), problems related to availability of drugs (9.0\%), financial difficulties $(6.2 \%)$ and deficiency in knowledge (5.5\%) were documented as common reasons for non-adherence. Group comparison was carried out to identify any association between moderate to low adherence with demographic data. There was no association between moderate to low adherence with age $(p=0.177)$, gender $(p=0.836)$, level of education $(p=0.084)$, expenses for medications per month $(p=0.728)$ or the number of tablets per day $(p=0.865)$. However, there was a statistical significance between moderate to low adherence with monthly income below twenty thousand rupees $(p=0.010)$. Complete group comparison was shown in (Table 5).

Although the patients were advised on post $\mathrm{PCl}$ pharmacological therapy following discharge, the awareness about the duration of aspirin (21.4\%) and Clopidogrel (14.5\%) therapy as well as the awareness on adverse effects of given medications (7.6\%) were very much low. Nevertheless, adverse effects such as gastrooesophageal reflux disease (37.2\%) due to aspirin, headache $(10.3 \%)$ with nitrate therapy, bleeding (major/ minor) (9.0\%) owing to dual antiplatelet therapy and myopathies/ muscle cramps (7.6\%) due to statin therapy were prevalent within the study group (Table 6). Importantly, there was no significant association of low medication adherence with adverse effects of the drugs $(p=0.557)$.

Patient satisfaction was assessed using PSQ-18 questionnaire and the results were summerzied under seven sub categories (Table 7). General satisfaction of the post $\mathrm{PCl}$ study population was $95.9 \%$. The satisfaction about technical quality with regard to $\mathrm{PCl}$ procedure and satisfaction about interpersonal skills of health care providers were equally high (98.6\%). Among the population, satisfaction about communication skills of health care providers was $87.6 \%$, satisfaction on expenditures for health system was $71.7 \%$ and satisfaction about time spent with health care providers was $84.1 \%$. Conversely, satisfaction about accessibility for health system and its convenience remained comparatively low (46.9\%). The low satisfaction on accessibility and convenience of health care system was significantly associated with male gender $(p=0.043)$ and higher education level $(p<0.001)($ Table-8). There was no significant association between age, monthly income and expenses for medications per month with any of the sub groups of patient satisfaction. There was no significant association between high patient satisfaction and drug adherence $(p=0.702)$.

Furthermore, we questioned about lifestyle modifications, especially dietary control and exercising. Even though most of the patients (95.9\%) were advised on dietary control, about half of the study group (59.0\%) was following advice. Difficulty in applying to all family members $(26.9 \%)$, lack of knowledge $(15.2 \%)$, occupation related problems $(9.7 \%)$ were highlighted as reasons for not following dietary advice. Similarly, $80.7 \%$ were advised on the importance of regular exercise yet only $38.6 \%$ were doing regular exercise with a mean duration of $3.55 \pm 1.81$ hours per week. Lack of knowledge (35.9\%), lack of time (22.1\%) and associated other illnesses (13.1\%) were emphasized as reasons for not following advice on regular exercise. 
Table 4. Responses given for the MMAS - 8 Questionnaire

\begin{tabular}{lrc}
\hline \multicolumn{1}{c}{ Variable name } & Result (n, \%) & No \\
\hline Question & $71(49.0 \%)$ & $74(51.0 \%)$ \\
\hline Do you sometimes forget to take pills? & $20(13.8 \%)$ & $125(86.2 \%)$ \\
\hline Did you miss your pills over past two weeks? & $07(4.8 \%)$ & $138(95.2 \%)$ \\
\hline Have you ever cut back or stop taking your medications? & $19(13.1 \%)$ & $126(86.9 \%)$ \\
\hline Do you forget to bring along your medications when you travel? & $143(98.6 \%)$ & $02(1.4 \%)$ \\
\hline Did you take all your medications yesterday? & $04(2.8 \%)$ & $141(97.2 \%)$ \\
\hline When symptoms are under control, do you stop taking your medicine? & $12(8.3 \%)$ & $133(91.7 \%)$ \\
\hline Do you ever feel hassled about sticking to your treatment plan? & $134(92.4 \%)$ & $11(7.6 \%)$ \\
\hline How often do you have difficulty to remembering to take all your medicine? & & 14\% \\
\hline
\end{tabular}

Table 5. Group comparison on moderate to low adherence with demographic data

\begin{tabular}{|c|c|c|c|}
\hline Variable name & & Result $(n, \%)$ & $P$ value \\
\hline \multirow[t]{2}{*}{ Age } & $<40$ years & $33(45.8 \%)$ & 0.177 \\
\hline & $>=40$ years & $25(34.2 \%)$ & \\
\hline \multirow[t]{2}{*}{ Gender } & Male & $47(40.5 \%)$ & 0.836 \\
\hline & Female & $11(37.9 \%)$ & \\
\hline \multirow[t]{2}{*}{ Level of education } & Below Ordinary Level & $30(34.1 \%)$ & 0.084 \\
\hline & Above Ordinary Level & $28(49.1 \%)$ & \\
\hline \multirow[t]{2}{*}{ Monthly Income } & $<$ Rs. $20000 /=$ & $31(44.3 \%)$ & 0.010 \\
\hline & >Rs. $20000 /=$ & $27(36.0 \%)$ & \\
\hline \multirow[t]{2}{*}{ Expenses for medications } & $<$ Rs.2000/= & $21(37.5 \%)$ & 0.728 \\
\hline & $>$ Rs. $2000 /=$ & $37(41.6 \%)$ & \\
\hline \multirow[t]{2}{*}{ Number of tablets } & Less than 7 & $31(41.3 \%)$ & 0.865 \\
\hline & More than 7 & $27(38.6 \%)$ & \\
\hline
\end{tabular}

\section{Table 6. Prevalence of adverse} effects of the drugs

\begin{tabular}{lc}
\hline Variable name & Result $(n, \%)$ \\
\hline Gastro-oesophageal reflux disease & $54(37.2 \%)$ \\
\hline Bleeding & $13(9.0 \%)$ \\
\hline Myopathies/muscle cramps & $11(7.6 \%)$ \\
\hline Headache & $15(10.3 \%)$ \\
\hline Cough & $2(1.4 \%)$ \\
\hline
\end{tabular}

\section{Discussion}

This study was conducted with the aim of evaluating medication adherence, patient satisfaction and their determinants in a group of post $\mathrm{PCl}$ patients. More than four third of the study population had moderate to high adherence for the treatment and the prevalence of low adherence was below ten percent. According to the literature, medication adherence of post $\mathrm{PCl}$ patients was observed to be around $70 \%{ }^{4,6}$ with one study done in Brazil in 2013 with a study population of 101 had demonstrate medication adherence to be $97 \%{ }^{3}$. Medication adherence in a group of post myocardial 
Table 7. Summary of the results: PSQ - 18

\begin{tabular}{lll}
\hline Variable name & \multicolumn{1}{c}{ Result (n, \%) } \\
\hline General satisfaction & Satisfied & Unsatisfied \\
\hline Technical Quality satisfaction & $139(95.9 \%)$ & $6(4.1 \%)$ \\
\hline Interpersonal Manner satisfaction & $143(98.6 \%)$ & $2(1.4 \%)$ \\
\hline Communication satisfaction & $143(98.6 \%)$ & $2(1.4 \%)$ \\
\hline Financial Aspect satisfaction & $127(87.6 \%)$ & $18(12.4 \%)$ \\
\hline Time spent with Doctor satisfaction & $104(71.7 \%)$ & $41(28.3 \%)$ \\
\hline Accessibility and convenience satisfaction & $122(84.1 \%)$ & $23(15.9 \%)$ \\
\hline
\end{tabular}

Table 8. Group comparison - Satisfaction on Accessibility and Convenience

\begin{tabular}{llrl}
\hline Variable name & & Results $(n, \%)$ & $P$ value \\
\hline \multirow{2}{*}{ Age } & $<40$ years & $33(45.8 \%)$ & 0.868 \\
& $>$ =40 years & $35(47.9 \%)$ & \\
\hline \multirow{2}{*}{ Gender } & Male & $59(50.9 \%)$ & 0.064 \\
& Female & $9(31.0 \%)$ & \\
\hline \multirow{2}{*}{ Level of education } & Below Ordinary Level & $30(34.1 \%)$ & $<0.001$ \\
& Above Ordinary Level & $38(66.7 \%)$ & \\
\hline \multirow{2}{*}{ Monthly Income } & <Rs.20000/= & $29(41.4 \%)$ & 0.244 \\
& $>$ Rs.20000/= & $39(52.0 \%)$ & \\
\hline
\end{tabular}

infarction patients was less, with $25 \%$ well adherence, $54 \%$ fairly adherent and $22 \%$ poorly adherent ${ }^{9}$. Therefore post $\mathrm{PCl}$ group have a satisfactory medication adherence compared to post myocardial infarction patients without interventions. Aghabekyan et $\mathrm{al}^{4}$ had shown age and expenditure for medications as independent predictors of non-adherence, which was in contrast with our study. However, monthly income had an influence on drug adherence of our population. There was a higher adherence level for dual antiplatelet therapy than general adherence, which are the most important drugs to prevent major adverse coronary events. This high adherence could be a result of patients' perception, as evident by our study; most of the patients do believe that continuation of medication is essential after the $\mathrm{PCl}$ while others continue to take medications as they were enforced to do so by the medical staff. Therefore discussion about the need and duration of antiplatelet and other medications with the patients before and after the $\mathrm{PCl}$ procedure is important for further improvement of medication compliance.

Nevertheless, awareness about dual antiplatelet therapy was very much low with in the study group. The duration for which dual antiplatelet therapy need to be continued is still an arbitrary point. Early discontinuation of dual antiplatelet therapy could be associated with stent thrombosis, myocardial re-infarction or even sudden cardiac death ${ }^{10,11}$. Thus, improving the knowledge about the duration and importance of continuing dual antiplatelet therapy following $\mathrm{PCl}$ among the patients is very much important. 
Prevalence of medication side effects among Sri Lankan population had not been assessed up to date. Antiplatelet associated bleeding (major or minor) was reported to be $8.9 \%{ }^{12}$, which is mostly the same for our population. Incident of major bleeding was documented as $2 \%{ }^{13,14}$ which need to be evaluated in our population in future studies. Prevalence of aspirin associated gastrooesophageal reflux disease is higher than the incidence noted in literature ${ }^{15,16}$.

There was a study where patient satisfaction was assessed under few subgroups and the results revealed $77.5 \%$ being generally satisfied, $95.9 \%$ satisfied with interpersonal manner and $88.2 \%$ were satisfied about communication ${ }^{4}$. The satisfaction about perceived health care of our population seems to be higher. In addition, this study had concluded that there was no statistical significance between high patient satisfaction and drug adherence ${ }^{4}$, which was the same for our study as well.

This is a single center experience. However being one of the largest cardiac centers in the country, we encounter patients from different areas of the country, making the study more generalized. The time gap after the stent placement was not accounted, resulting different period of time which may cause an impact on the assessment of medication adherence. Also we collected self-reported information on medication adherence and patient satisfaction, which can be subjected to reporting bias. Correlation between health status and medication adherence was not assessed in our study, which will be a good implication for further studies.

In conclusion, majority of the patients had moderate to high adherence to pharmacological therapy and low adherence was influenced by monthly income. On the other hand the awareness on pharmacological therapies is not satisfactory. Interestingly, patient satisfaction remained high under most sub categories. The accessibility of health care service need to be further improved. Finally, there was no association between high patient satisfaction and drug adherence.

By considering all the outcomes, formation of a well descriptive discharge plan will be important.

Considering above mentioned limitations, further study designs should take an account on time since stenting. Similarly, further studies are needed to assess the impact of medication adherence on clinical outcomes. Descriptive qualitative studies may provide further information on main obstacles to low medication adherence as well as opportunities for further increase of compliance.

\section{Acknowledgment}

We would like to acknowledge to all the medical and para-medical staff members at the Cardiology Unit, Teaching Hospital Kandy, who gave their enumerate support to conduct this study. We all express our gratitude to all the patients who kindly gave consent and participated in this study.

\section{Funding}

This research received no grant from any funding agency in the public, commercial or not-for-profit sectors.

\section{Disclosures} interest.

The Author (s) declare (s) that there is no conflict of

\section{References}

1. Cardiovascular diseases (CVDs) Fact sheet $N^{\circ} 317$ : World Health Organization web site, Updated January 2015 http:/ /www.who.int/mediacentre/factsheets/fs317/en/Accessed July 23, 2015.

2. Katulanda P, Liyanage IK, Caldera R, Constantine GR, Sheriff MHR, Matthews DR. Prevalence of ischaemic heart disease and risk factors in Sri Lanka; Sri Lanka Medical Association - 123rd Annual Academic Sessions; 2010_.53pp

3. Adherence to Long-Term Therapies: Evidence for Action. World Health Organization Web site. 2003 http:// www.who.int/medicinedocs/collect/medicinedocs/pdf/ s4883e/s4883e.pdfAccessed July 23, 2015.

4. Aghabekyan S, Thompson ME, Abrahamyan L. Medication noncompliance and patient satisfaction following percutaneous coronary intervention:J Interventional Cardiology. 2012; 25(5): 469-75.

5. Coelho M, Costa Ede C, Richter VC, Dessotte CA, Ciol MA, Schmidt A, Dantas RA, Rossi LA, Furuya RK. Perceived health status and pharmacological adherence of patients who underwent percutaneous coronary intervention; Rev Gaucha Enferm 2013; 34(3): 86-94.

6. Rushworth GF, Cunningham S, Mort A, Rudd I, Leslie SJ., Patient specific factors relating to medication adherence in a post percutaneous coronary intervention cohort.; Int J Pharm Pract. 2012; 20(4 vc): 226-37.

7. Morisky DE, Ang A, Krousel-Wood M, Ward HJ. Predictive validity of a medication adherence measure in an outpatient setting. J Clin Hypertens (Greenwich). 2008; 10(5): 348-54.

8. Marshall GN, Hays RD. The Patient Satisfaction Questionnaire Short-Form (PSQ-18) RAND Corporation. 1994; P-7865. 
9. MikhayilMelikov. A Study on Adherence to Physicians' Instructions for Physical Activity among Patients with FirstTime Acute Myocardial Infarction. College of Health Sciences, Yerevan, 2009.

10. Thim T, Johansen MB, Chisholm GE, et al. Clopidogrel discontinuation within the first $\mathrm{T}$, et al. Clinical impact of extended dual antiplatelet therapy after percutaneous coronary interventions in the drug-eluting stent era: a meta-analysis of randomized trials. Eur Heart J. 2012; 33(24): 3078-87. Epub 2012 Oct 22.

12. Aronow HD et al. Bleeding risk associated with 1 year of dual antiplatelet therapy after percutaneous coronary intervention: Insights from the Clopidogrel for the Reduction of Events During Observation (CREDO) trial. Am Heart J. 2009; 157(2): 369-74.
13. Tanigawa $T$, Watanabe $T$, Nadatani $Y$, et al; Gastroin-testinal bleeding after percutaneous coronary inter-vention. Digestion 2011; 83(3): 153-60.

14. Navarese EP, Andreotti F, Schulze V, et al. Optimal duration of dual antiplatelet therapy after percutaneous coronary intervention with drug eluting stents: meta analysis of randomized controlled trials. BMJ 2015; 16: 350.

15. Saberi-Firoozi M, Khademolhosseini F, et al. Risk factors of gastroesophageal reflux disease in Shiraz, southern Iran. World J Gastroenterol 2007; 13(41): 5486-91.

16. Cayla G, Collet JP, Silvain J, Thiefin G, Woimant F, MontalescotG. Prevalence and clinical impact of Upper Gastrointestinal Symptoms in subjects treated with low dose aspirin: the UGLA survey. Int J Cardiol. 2012; 156(1): 69-75. 